\title{
The Relationship Between Physical Activity and Sleep Status Among Iranian Older Adults: A Cross-Sectional Study
}

\author{
Samaneh Aliabadi \\ Birjand University of Medical Sciences \\ Fatemeh Zarghami \\ Tabriz University of Medical Sciences \\ Akram Farhadi \\ Bushehr University of Medical Sciences \\ Farshad Sharifi \\ Tehran University of Medical Sciences \\ Mitra Moodi ( $\square$ mitra_m2561@yahoo.com) \\ Birjand University of Medical Sciences
}

\section{Research Article}

Keywords: Aged, Sleep Quality, Sleep satisfaction, Sleep efficiency, Sleep duration, Exercise

Posted Date: October 13th, 2021

DOI: https://doi.org/10.21203/rs.3.rs-963683/v1

License: () (i) This work is licensed under a Creative Commons Attribution 4.0 International License. Read Full License 


\section{Abstract}

Background: Sleep disorders have a significant impact on physical and mental health among aged population. This study was aimed to determine the relationship between different levels of physical activity (PA) and domains of sleep status in aged population in Birjand, Iran.

Methods: This descriptive-analytical study was performed on 1740 individuals $\geq 60$ years in urban and rural regions of Birjand. Longitudinal Ageing Study Amsterdam Physical Activity Questionnaire (LAPAQ), a sociodemographic and a sleep status questionnaire were used to collect data. Analyses of variance (ANOVA), univariate, multiple linear and logistic regressions were used to analyze the data.

Results: The mean age of the participants was $69.73 \pm 7.56$ years. About $54.08 \%$ of participants had low PA. People with moderate to high PA had higher sleep quality, sleep satisfaction and sleep efficiency compared to inactive people ( $p<0.05)$; but PA was significantly inversely related to sleep duration.

According to univariate linear regression model, both low and moderate to high PA were good predictors of sleep quality, sleep efficiency. Moderate to high PA predicted high sleep satisfaction and sleep duration in the participants $(p<0.05)$.

Conclusions: Physical activity, particularly at moderate to high levels, results in higher quality, satisfaction and efficiency of sleep in the elderly. The most influential factor on the relationship between PA and sleep is depressed mood. Therefore, in using the PA to improve sleep status of the elderly it is recommended to also focus on reducing the depression.

\section{Background}

Aging is associated with major changes in the sleep quality, sleep structure, and circadian rhythm (sleep and wakefulness) [1]. Results of scientific research have reported significant changes in the structure of sleep in the aging process, including changes in the ratio of sleep spent in different stages [2,3], increased sleep disorders [3, 4], decreased sleep quality [5], decreased sleep efficiency and increased early morning wakefulness [6].

It is estimated that $30-45 \%$ of the world's population suffers from insomnia and with increasing the age, this rate also increases [7]. Half of the elderly (50\%) complain of the problems associated with going to sleep or maintaining sleep [8]. The prevalence of sleep disorders in the Iranian elderly is estimated around $48.9 \%$ [9]. Sleep accounts for about one-third of daily activity [10], and studies have shown that short sleep duration is associated with obesity, type 2 diabetes, hypertension, and cardiovascular diseases $[11,12]$. Sleep disorders in older population may lead to depression, deterioration of balance which can result in falls, memory disorders, irritability, poor quality of life, mood swings, and anxiety $[13,14]$. All of these conditions destroy the functional ability and can cause dependency to others $[15,16]$. Pharmacological approaches have been the main solution to solve the sleep problems, but they are not always effective or safe [10] and may have common side effects such as drowsiness, restlessness, and interactions with other drugs [17]. Recently, non-pharmacological interventions have been proposed as a better method in the treatment of sleep disorders with more durability and less side effects $[18,19]$.

Among the non-pharmacological treatments for sleep disorders, regular Physical Activity (PA) causes relaxation and an increase in central body temperature which is known as a good method to start and maintain the sleep [19]. Various mechanisms that describe the relationship between exercise and sleep such as thermoregulation, anxiolytic and antidepressant, body restoration and levels of serotonins and adenosine have been explored [20].

According to World Health Organization (WHO) guidelines, seniors with age 65 years and older are recommended to perform at least 150 minutes of moderate-intensity PA per week or at least 75 minutes of high-intensity aerobic exercise per week [21]. Regular PA reduces the incidence of cardiovascular, metabolic and musculoskeletal disorders, improves sleep and overall health and decreases the mortality $[22,23]$. The results of studies have shown the relationship and positive effect of PA on sleep in the elderly $[19,24-27]$. Zar et al. examined the relationship and effectiveness of physical activity on the sleep quality 
in postmenopausal women, the results of which showed that the sleep quality of active postmenopausal women was better than other women (24). Therefore, PA is a cheap, easy, accessible and simple way to improve the sleep [6].

Numerous studies investigated the relationship between PA and sleep on different age groups, but studies in the older population are limited. It is important to consider that decrease in quality and satisfaction of sleep in the old ages, has adverse effects on the physical and mental health and recovery of various illnesses. After a comprehensive literature review, it was discovered that there is not such research conducted in Iran. Therefore, the present study is designed to examine the relationship between different levels of PA and domains of sleep status (duration, efficiency, satisfaction and quality) in Birjand using the Longitudinal Ageing Study Amsterdam Physical Activity Questionnaire (LAPAQ) for the first time in the Iranian elderly.

\section{Methods}

\section{Study population}

This study was carried out using the baseline data of Birjand Longitudinal Aging Study (BLAS), which is a cohort study with the first phase began in 2018 and showed the health status of the elderly. In this study, the elderly living in urban and rural areas of Birjand city were studied by multi-stage stratified cluster random sampling. The inclusion criterion for this study was age $\geq 60$ years and had the ability to participants. Those who were completely bedridden, very severe cognitive impairment and Alzheimer's disease that unable to communicate or had a very short life expectancy (less than 6 months) were excluded from the study. Data of 1740 participants who completed the BLAS questionnaire were examined. Details of the sampling method were discussed elsewhere [28].

Sociological variables, variables related to sleep and PA were examined. Age of the participants was divided into three categories: 60-69 years, $70-79$ years and $\geq 80$ years. Data related to education, chronic diseases and smoking status were collected from the participants. Wealth index was calculated using a factor analysis on ten dummy variables about household assets. The first loading factor was considered as wealth index and it was categorized into five groups according to quintile cutoff. Body mass index (BMI) was calculated by dividing the weight $(\mathrm{kg})$ by square of height (in meter). The weight and height was measured using standard instrument with precision of $0.1 \mathrm{~kg}$ and 0.5 centimeter, respectively. Depressed mood and severity of depression was evaluated using the Persian version of Patient Health Questionnaire-9 (PHQ-9). The psychometric properties of this questionnaire (PHQ-9) were assessed in Iran [29].

\section{Sleep Status (outcome)}

Multiple characteristics of sleep (duration, quality, satisfaction, and efficiency) were assessed using seven selected questions from the Pittsburgh Sleep Quality Index (PSQI). The PSQI is a standard questionnaire for assessing sleep quality in the past month that has 18 questions with 7 scales. Hedayat et al. reported the validity of this questionnaire using the test-retest method of 0.78 and the internal consistency method (Cronbach's alpha) of 0.86 [30]. Moreover, participants were asked if they take regular naps. If they answered "yes", then, they were asked, "How long is it?"

Sleep duration was calculated by reducing the time to falling asleep at night and the time of waking up in the morning. Then the mean and standard deviation of sleep duration in minutes were calculated. The questions related to measuring sleep quality and sleep satisfaction had four Likert type choices (very good, relatively good, relatively bad, and very bad); the last two choices were considered poor sleep quality and sleep satisfaction.

\section{Physical activity (exposure)}

Longitudinal Ageing Study Amsterdam Physical Activity Questionnaire (LAPAQ) was used to assess the PA. The LAPAQ with 23 questions examines the intensity and duration of daily activities such as walking outdoors, cycling, gardening, household and sports activities during the previous two weeks. Moreover, at the end of the questionnaire, the respondents are asked whether the activity pattern of the last two weeks represents the rest of the year. When this pattern does not reflect the activity 
of the whole year, the participants answer the reasons. Later, the individual's PA is calculated and classified according to the scoring protocol which is explained in the study by Nam GB [31]. The total score of the LAPAQ for each activity in 2 weeks was calculated by multiplying the frequency of the activity with the duration score. The total amount of PA was calculated by summing the scores of the individual activities in the last two weeks (Met-minutes/week). In this study, PA status of participants was classified into three levels: totally inactive (less than 300 METs minutes per week), low PA (300-600 METs minutes per week) and moderate to high PA (more than 600 METs minutes per week).

Stel et al. examined the validity of the LAPAQ vs. 7-day PA notebook and a 7-day pedometric recorded of steps and energy expenditure. The LAPAQ was highly correlated to the 7-day diary $(r=0.68, P<.001)$ and moderately with the pedometer $(r=0.56$, $\mathrm{P}<$.001). The repeatability of the LAPAQ was reasonably good (weighted kappa: 0.65-0.75) [32].

\section{Statistical analysis}

The collected data of BLAS were stored online in Endocrine and Metabolism Research Institute servers and in different files and the data related to each participant was stored under a unique code. All files were merged after refining and coding. Data analysis was performed using Stata version 12 software and $p<0.05$ was considered as significant threshold. Mean standard deviation and frequency statistical indices were used to describe the data. Analysis of variance (ANOVA) was used to compare the average duration and efficiency of sleep among the elderly with different levels of PA.

Then, univariate and multiple linear and logistic regression models were used to estimate sleep duration and efficiency according to different levels of PA and its outcomes. Moreover, the sleep quality and sleep satisfaction were defined as dummy variables; very bad and bad quality vs. good and very good sleep quality also very unsatisfied and unsatisfied vs. satisfied and very satisfied sleep satisfaction. Univariate and multiple regression models were utilized for assessment of the relation between PA as ordinal variable and the sleep characteristics.

\section{Results}

In the present study, the data gathered from 1740 old people were analyzed. The mean age of the participants was $69.73 \pm 7.56 y$ ears. Of 1740 participants, $813(46.72 \%)$ were in the age group of $60-69$ and the majority of them (52.3\%) were women. Low PA was observed in 941 (54.08\%) of the participants. Of all the participants, 893 (51.32\%) individuals were illiterate, 96 (5.52\%) persons smoked and 311 (17.87\%) persons had depressed mood (Table 1). 
General characteristics of the participants.

\begin{tabular}{|c|c|c|c|}
\hline & & $\begin{array}{l}\text { Total Participants } \\
\mathrm{N}=1740\end{array}$ & \\
\hline & & Mean or Number & SD or Percent \\
\hline Age (years) & $60-69$ years & 813 & $46.72 \%$ \\
\hline & $70-79$ years & 613 & $35.23 \%$ \\
\hline & $80+$ years & 314 & $18.05 \%$ \\
\hline Sex & Female & 910 & $52.30 \%$ \\
\hline & Male & 830 & $47.70 \%$ \\
\hline Mean Years of schooling (SD) & & 3.717 & 4.806 \\
\hline Current Smoker & No & 1644 & $94.48 \%$ \\
\hline & Yes & 96 & $5.52 \%$ \\
\hline Depressed Mood (by PHQ-9) & No & 1429 & $82.13 \%$ \\
\hline & Yes & 311 & $17.87 \%$ \\
\hline Having Chronic Disease & No & 750 & $43.10 \%$ \\
\hline & Yes & 990 & $56.90 \%$ \\
\hline Mean BMI (SD) Kg/m² & & 25.99 & 5.27 \\
\hline
\end{tabular}

Findings showed sleep duration, sleep quality, sleep satisfaction and sleep efficiency significantly differed in three groups of the PA $(p<0.05)$. This means that elderly with higher PA had higher sleep quality, sleep satisfaction and sleep efficiency than inactive participants; However, PA was inversely related to sleep duration, so that the elderly with moderate to high PA slept less than other elderly $(p<0.05)$ (Table 2$)$.

Table 2 Domains of sleep status among different levels of physical activity. 


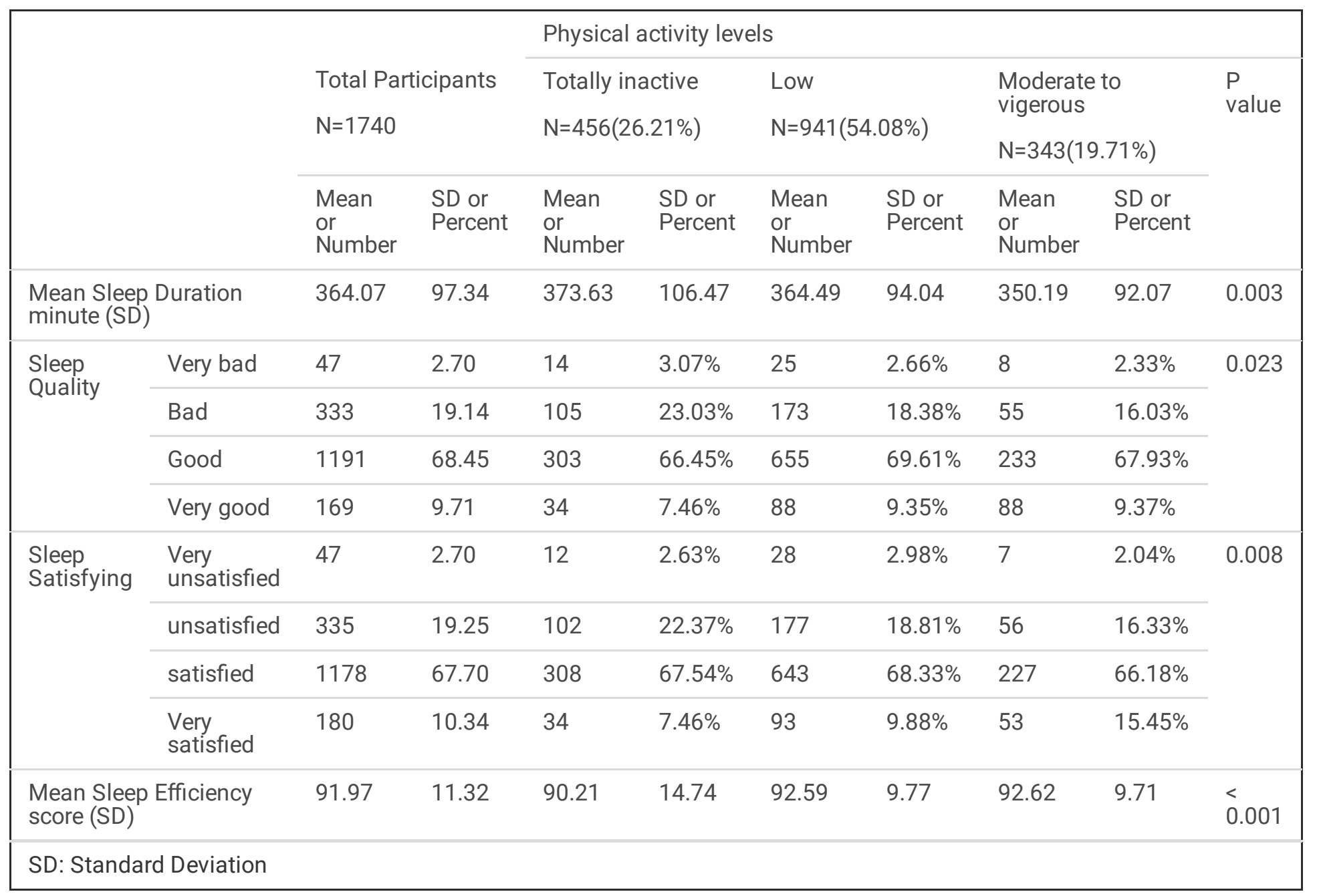

Univariate and multiple linear and logistic regression analysis were used to predict sleep characteristics according to different levels of PA in the elderly. Referring to the Table 3, moderate to high PA predicted less sleep duration in the elderly. In model 3, the elderly in the moderate to high PA group, significantly slept less than other groups [B standardized $=-0.083, p=0.005$ ]. 
Table 3

Association of real sleep duration at night and physical activity in linear regression models

\begin{tabular}{|c|c|c|c|c|c|}
\hline & & $\beta$ coefficient & SE $\beta$ & $\begin{array}{l}\boldsymbol{\beta} \\
\text { standardized }\end{array}$ & $P$ value \\
\hline \multicolumn{6}{|l|}{ Univariate Model } \\
\hline \multirow[t]{3}{*}{ Physical Activity } & Inactivate $(\mathrm{N}=456)$ & Reference & & & \\
\hline & Low $(\mathrm{N}=941)$ & -9.141 & 5.539 & -0.047 & 0.099 \\
\hline & Moderate to High $(\mathrm{N}=343)$ & -23.447 & 6.938 & -0.096 & 0.001 \\
\hline \multicolumn{6}{|l|}{ First Model } \\
\hline \multirow[t]{3}{*}{ Physical Activity } & Inactivate $(\mathrm{N}=456)$ & Reference & & & \\
\hline & Low $(\mathrm{N}=941)$ & -7.730 & 5.558 & -0.040 & 0.164 \\
\hline & Moderate to High $(\mathrm{N}=343)$ & -20.460 & 7.044 & -0.084 & 0.004 \\
\hline \multicolumn{6}{|l|}{ Second Model } \\
\hline \multirow[t]{3}{*}{ Physical Activity } & Inactivate $(\mathrm{N}=456)$ & Reference & & & \\
\hline & Low $(\mathrm{N}=941)$ & -6.646 & 5.589 & -0.034 & 0.235 \\
\hline & Moderate to High ( $\mathrm{N}=343$ ) & -17.890 & 7.146 & -0.073 & 0.012 \\
\hline \multicolumn{6}{|l|}{ Third Model } \\
\hline \multirow[t]{3}{*}{ Physical Activity } & Inactivate $(\mathrm{N}=456)$ & Reference & & & \\
\hline & Low $(\mathrm{N}=941)$ & -7.702 & 5.594 & -0.039 & 0.169 \\
\hline & Moderate to High ( $\mathrm{N}=343$ ) & -20.232 & 7.205 & -0.083 & 0.005 \\
\hline \multicolumn{6}{|c|}{ First Model: adjusted for age, sex, and education years } \\
\hline \multicolumn{6}{|c|}{ Second Model: First Model + current smoking + Body Mass Index } \\
\hline \multicolumn{6}{|c|}{ Third Model: Second Model + HX of chronic disease + depressed mood } \\
\hline
\end{tabular}

According to the univariate model in Table 4, both low and moderate to high levels of PA predicted good sleep quality in the elderly [OR $0.75,95 \% \mathrm{Cl} 0.58-0.98, p=0.035$ ] [OR $0.64,95 \% \mathrm{Cl} 0.45-0.90, p=0.010$ ]. With the inclusion of the depression variable into the third model, the association between PA and quality of sleep disappeared $(p>0.05)$. 
Table 4

Association of self-reported quality of sleep with physical activity in logistic regression models

\begin{tabular}{|c|c|c|c|c|}
\hline & & Odds Ratio & $\mathrm{Cl} 95 \%$ OR & $P$ value \\
\hline \multicolumn{5}{|l|}{ Univariate Model } \\
\hline \multirow[t]{3}{*}{ Physical Activity } & Inactivate $(\mathrm{N}=456)$ & Reference & & \\
\hline & Low $(\mathrm{N}=941)$ & 0.755 & $0.581-0.980$ & 0.035 \\
\hline & Moderate to High ( $N=343$ ) & 0.637 & $0.451-0.899$ & 0.010 \\
\hline \multicolumn{5}{|l|}{ First Model } \\
\hline \multirow[t]{3}{*}{ Physical Activity } & Inactivate $(\mathrm{N}=456)$ & Reference & & \\
\hline & Low (N = 941) & 0.802 & $0.614-1.046$ & 0.103 \\
\hline & Moderate to High ( $N=343$ ) & 0.710 & $0.498-1.012$ & 0.058 \\
\hline \multicolumn{5}{|l|}{ Second Model } \\
\hline \multirow[t]{3}{*}{ Physical Activity } & Inactivate $(\mathrm{N}=456)$ & Reference & & \\
\hline & Low $(N=941)$ & 0.803 & $0.616-1.048$ & 0.107 \\
\hline & Moderate to High ( $\mathrm{N}=343$ ) & 0.717 & $0.503-1.023$ & 0.067 \\
\hline \multicolumn{5}{|l|}{ Third Model } \\
\hline \multirow[t]{3}{*}{ Physical Activity } & Inactivate $(\mathrm{N}=456)$ & Reference & & \\
\hline & Low $(\mathrm{N}=941)$ & 0.902 & $0.680-1.196$ & 0.475 \\
\hline & Moderate to High ( $N=343$ ) & 0.944 & $0.649-1.373$ & 0.763 \\
\hline \multicolumn{5}{|c|}{ First Model: Adjusted for age and sex } \\
\hline \multicolumn{5}{|c|}{ Second Model: First Model + BMI + chronic disease } \\
\hline \multicolumn{5}{|c|}{ Third Model: Second Model + depressed mood } \\
\hline
\end{tabular}

According to the univariate model in Table 5, moderate to high PA was a predictor of high sleep satisfaction in the elderly [OR $0.67,95 \% \mathrm{Cl} 0.48-0.95, \mathrm{p}=0.026]$. With the inclusion of the depression variable into the third model, the association between PA and sleep satisfaction disappeared [OR $0.90,95 \% \mathrm{Cl} 0.62-1.33, \mathrm{p}=0.610]$. 
Table 5

Association of sleep satisfaction with physical activity in logistic models

\begin{tabular}{|c|c|c|c|c|}
\hline & & Odds Ratio & $\mathrm{Cl} 95 \%$ OR & $P$ value \\
\hline \multicolumn{5}{|l|}{ Univariate Model } \\
\hline \multirow[t]{3}{*}{ Physical Activity } & Inactivate $(\mathrm{N}=456)$ & Reference & & \\
\hline & Low $(\mathrm{N}=941)$ & 0.836 & $0.643-1.086$ & 0.180 \\
\hline & Moderate to High $(\mathrm{N}=343)$ & 0.675 & $0.478-0.953$ & 0.026 \\
\hline \multicolumn{5}{|l|}{ First Model } \\
\hline \multirow[t]{3}{*}{ Physical Activity } & Inactivate $(\mathrm{N}=456)$ & Reference & & \\
\hline & Low $(\mathrm{N}=941)$ & 0.883 & $0.676-1.153$ & 0.361 \\
\hline & Moderate to High $(\mathrm{N}=343)$ & 0.744 & $0.521-1.061$ & 0.102 \\
\hline \multicolumn{5}{|l|}{ Second Model } \\
\hline \multirow[t]{3}{*}{ Physical Activity } & Inactivate $(\mathrm{N}=456)$ & Reference & & \\
\hline & $\operatorname{Low}(\mathrm{N}=941)$ & 0.865 & $0.659-1.134$ & 0.293 \\
\hline & Moderate to High $(\mathrm{N}=343)$ & 0.705 & $0.490-1.015$ & 0.060 \\
\hline \multicolumn{5}{|l|}{ Third Model } \\
\hline \multirow[t]{3}{*}{ Physical Activity } & Inactivate $(\mathrm{N}=456)$ & Reference & & \\
\hline & Low $(\mathrm{N}=941)$ & 0.965 & $0.721-1.285$ & 0.806 \\
\hline & Moderate to High ( $\mathrm{N}=343$ ) & 0.905 & $0.617-1.328$ & 0.610 \\
\hline \multicolumn{5}{|c|}{ First Model: Adjusted for age and sex } \\
\hline \multicolumn{5}{|c|}{ Second Model: First Model + education year + wealth index } \\
\hline Third Model: Secc & nd Model + depressed mood & & & \\
\hline
\end{tabular}

Finally, the results of this study showed that according to the univariate model low and moderate to high PA predicted good sleep efficiency in the elderly. [OR $0.68,95 \% \mathrm{Cl} 0.51-0.89, \mathrm{p}=0.007$ ], [OR $0.63, \mathrm{Cl} 0.46-0.95, \mathrm{p}=0.026$ ] According to model 1 , low PA was a good predictor of sleep efficiency in older adults [OR $0.72,95 \% \mathrm{Cl} 0.54-0.96, \mathrm{p}=0.026$ ]. With the inclusion of the depression variable into the model, the relationship between PA and sleep efficiency disappeared [OR $0.78,95 \% \mathrm{Cl} 0.58-1.04$, $p=0.089$ ]. For more information please refer to Table 6 . 
Table 6

Association of habitual sleep efficiency and physical activity in logistic models

\begin{tabular}{|c|c|c|c|c|}
\hline & & Odds Ratio & $\mathrm{Cl} 95 \%$ OR & $P$ value \\
\hline \multicolumn{5}{|l|}{ Univariate Model } \\
\hline \multirow[t]{3}{*}{ Physical Activity } & Inactivate $(\mathrm{N}=456)$ & Reference & & \\
\hline & Low $(\mathrm{N}=941)$ & 0.679 & $0.513-0.898$ & 0.007 \\
\hline & Moderate to High $(\mathrm{N}=343)$ & 0.663 & $0.461-0.953$ & 0.026 \\
\hline \multicolumn{5}{|l|}{ First Model } \\
\hline \multirow[t]{3}{*}{ Physical Activity } & Inactivate $(\mathrm{N}=456)$ & Reference & & \\
\hline & Low $(\mathrm{N}=941)$ & 0.723 & $0.543-0.963$ & 0.026 \\
\hline & Moderate to High $(\mathrm{N}=343)$ & 0.743 & $0.509-1.083$ & 0.123 \\
\hline \multicolumn{5}{|l|}{ Second Model } \\
\hline \multirow[t]{3}{*}{ Physical Activity } & Inactivate $(\mathrm{N}=456)$ & Reference & & \\
\hline & $\operatorname{Low}(\mathrm{N}=941)$ & 0.776 & $0.579-1.040$ & 0.089 \\
\hline & Moderate to High $(\mathrm{N}=343)$ & 0.881 & $0.599-1.296$ & 0.520 \\
\hline \multicolumn{5}{|c|}{ First Model: Adjusted for age and sex } \\
\hline \multicolumn{5}{|c|}{ Second Model: First Model + depressed mood } \\
\hline
\end{tabular}

\section{Discussion}

\section{Interpretation of findings}

The aim of this study was to determine the relationship between different intensity of PA and sleep status among the elderly in Birjand. The findings showed that there is a significant difference in most domains of sleep status between physically active and inactive participants. In other words, active elderly had better sleep quality, sleep satisfaction and sleep efficiency than inactive elderly. These results are consistent with the findings of other studies [33-35]. It seems that many physiological changes during PA (e.g., increased body temperature and melatonin secretion, improved heart rate and immune function) could potentially promote sleep and reduce depressive symptoms [34].

The results of this study showed that with increasing levels of PA, the quality of sleep increases. This is consistent with results of some studies $[24,25,33,34,36]$. These findings support the importance of maintaining daily levels of PA to improve sleep quality in the elderly. On the other hand, our findings were in contrast to the results of Sahin et al. and Wu et al. [5, 37]. This difference may be due to differences in study design, PA and sleep measurement tools, and the lack of control over potential confounders.

Most previous research has focused on the relationship between PA and sleep quality; however, the relationship between PA and sleep duration was examined in this study. Our Findings showed the level of PA was inversely related to duration of sleep. Kredlow et al. in their meta-analysis study, found the effect of exercise on sleep duration in the elderly to be significant but small [35]. The results of our study contradict the findings of some studies that found high PA leads to longer sleep duration $[10,36,38,39]$. The differences may be due to differences in the type of measurement tools, PA leveling, the average age of participants and differences between place of residence (nursing homes or community). Moreover, as the population of our study were a mixed of rural and urban residents, it is possible that more physically active older adults lived in rural regions and these individuals usually start to gardening at early morning. In order to assess this theory, we compared the level 
of PA in urban and rural region and we found the elderly lived in rural region were significantly more physically active (data was not showed).

In this study, the elderly who had higher PA were more satisfied with their sleep. This finding is in line with the results of Jacobs et al.' and Park et al.'s studies [40,41]. However, the hypothesis regarding the association between the demographic variables (e.g., age, gender, and race) and poor satisfaction with sleep was not supported and PA was subcategory of health behavior and had no relationship with sleep satisfaction in Abraham et al. study [42]. Health care providers need to identify poor sleep satisfaction in the elderly and address non-pharmacological methods, especially exercise, to improve sleep because seniors rarely discuss sleep complaints during routine clinic visits, and may incorrectly use over-the-counter (OTC) prescription sleep medications [43].

The results of this study indicated that the elderly with high PA, had high sleep efficiency which is in line with the result of Kredlow et al.' and Zar et al.' studies [24, 35]. But Murry et al. found that a moderate to vigorous PA and time spent outdoors had a significant effect on predicting total sleep time but had no effect on predicting sleep efficiency. Women may spend more time outdoors in the afternoon and spend more time in bed but have less sleep efficiency [10]. The differences in findings may be due to differences in the mean age of the study population, PA and sleep measurement tools and the effect of outdoor activity time factor on sleep efficiency in Murry study [10].

According to our findings, it seems that the most influential factor on the relationship between PA and sleep in the elderly was depressed mood. Therefore, it is more likely that by reducing depression, PA has a positive effect on sleep status. As observed in most regression tables, the relationship between PA and sleep characteristics disappeared with the entry of the depressed mood variable into the models. Some studies have shown the positive effects of aerobic exercise on sleep quality and the relationship between reducing depressive symptoms and improving sleep quality [20]. Garfiled et al. found that in the group with elevated depressive symptoms only, physical activity was positively associated with sleep duration in models adjusted for all covariates (age, sex, wealth, ethnicity, smoking, alcohol consumption, BMI, long-standing illness) across low, moderate and high PA groups, in comparison to the sedentary group[38]. Silva et al. and Hsu et al. found a negative effect of depression on sleep quality and PA in the elderly $[44,45]$. According to the Diagnostic and Statistical Manual of Mental Disorders ${ }^{[1]}$, a change in sleep status is one of the criteria for diagnosing depression. A significant number of depressed patients complain of a general deterioration in their sleep. Furthermore, some review studies have shown that PA reduces depression symptoms in the old people [44]. Among the most-accepted explanations for the benefits of physical exercise in treating depression are the increases in the release of neurotransmitters such as serotonin, noradrenaline, and dopamine [46], as well as endorphins, which promote a general feeling of well-being, relieving depression and producing a feeling of content and of willingness to do things [47].

\section{Strengths and limitations}

Our study has several strengths and limitations. This study is part of the first phase of the BLAS and has a sufficient sample size with representative sample for older population, which allows us to conduct a comprehensive analysis. We examined the relationship between different levels of PA with domains of sleep status using the LAPAQ for the first time in Iranian elderly. We used the valid instruments for evaluation of PA and sleep status among aged people.

The first limitation of this study is that we did not exclude people who were diagnosed with sleep disorders or those taking sleeping medications. The other limitation is the very frail and completely bedridden older adults might not be able to participate in study. Our analysis was limited to cross-sectional data, and we did not examine the longitudinal nature of the relationship between PA and sleep domains.

[1] DSM-V-tr, 2014

\section{Conclusions}

Page $11 / 15$ 
Physical activity, particularly moderate to high PA, results in higher sleep quality, sleep satisfaction and sleep efficiency in the elderly. The most influential factor on the relationship between PA and sleep in the elderly is depressed mood. Therefore, targeting depression is important approach in designing interventional programs to use PA in addressing sleep disorders among old people. Designing interventional studies also are recommended to compare the effect of various physical activities on sleep dimensions in the elderly, especially in those with depression. Finally, it is recommended to conduct similar research in other parts of the country to better understand physical activity and other non-pharmacological interventions (e.g., sleep hygiene education, hypnotherapy, cognitive-behavioral therapy, massage, music, acupoints massage), to improve the sleep status in elderly with cultural and geographical differences.

\section{Abbreviations}

PA: Physical Activity; ANOVA: Analysis of Variance; LAPAQ: Longitudinal Ageing Study Amsterdam Physical Activity Questionnaire; BLAS: Birjand Longitudinal Aging Study; WHO: World Health Organization; DSM: Diagnostic and Statistical Manual of Mental Disorders

\section{Declarations}

\section{Acknowledgments}

We would like to thank the Vice Chancellor in Research of Birjand University of Medical Sciences and the Elderly Health Research Center of Endocrinology and Metabolism Research Institute in Tehran University of Medical Sciences, all questioners and also all the elderly participants in the study and their families.

\section{Authors' contributions}

SA, MM and FS substantially contributed to the conception and design of the work, and interpreted data. FS led the analysis, MM led data collection, and SA wrote the manuscript. AF and FZ contributed to translation, review and edit the manuscript. All authors critically revised and approved the final manuscript.

\section{Funding}

This project was approved and funded by Birjand University of Medical Sciences (BUMS) (grant number: 5122).

\section{Availability of data and materials}

The datasets used and/or analyzed during the current study are available from the corresponding author on reasonable request and with permission of the Birjand University of Medical Sciences (BUMS).

\section{Ethics approval and consent to participate}

This study was approved by ethical committee of Birjand University of Medical Sciences (Ethical Code: IR.BUMS.Rec.1398.275) in accordance with the principles of the Declaration of Helsinki. Written informed consent was obtained from all subjects. Moreover, in cases of dementia (AMTS $<7$ ), another informed consent was signed by a caregiver or legal guardian of the participants.

\section{Consent for publication}

Not applicable.

\section{Competing interests}

The authors declare that they have no competing interests. 


\section{Author details}

${ }^{1}$ Social Determinants of Health Research Center, School of Nursing and Midwifery, Vice-Chancellor's Office in Treatment Affairs, Birjand University of Medical Sciences, Ghafari Street, Birjand, Iran.

${ }^{2}$ Department of Gerontology, Faculty of Health, School of Health Education and Promotion, Tabriz University of Medical Science, Tabriz, Iran.

2 National Elites Foundation, Center for International Science and Technology Cooperation (CISTC), Tehran, Iran

${ }^{3}$ Department of Health Education and Promotion, School of Health, Bushehr University of Medical Sciences, Bushehr, Iran.

${ }^{4}$ Elderly Health Research Center, Endocrinology and Metabolism Population Sciences Institute, Tehran University of Medical Sciences, Tehran, Iran.

${ }^{5}$ Social Determinants of Health Research Center, Department of Health Promotion and Education, School of Health, Birjand University of Medical Sciences, Ghafari Street, Birjand, Iran.

\section{References}

1. Reid KJ, Martinovich Z, Finkel S, Statsinger J, Golden R, Harter K, et al. Sleep: a marker of physical and mental health in the elderly. Am J Geriatr Psychiatry 2006;14(10):860-6. https://doi.org/10.1097/01.JPG.0000206164.56404. ba.

2. Neikrug AB, Ancoli-Israel S. Sleep disorders in the older adult_a mini-review. Gerontology 2010;56(2):181-9. https://doi.org/ 10.1159/000236900.

3. Moraes W, Piovezan R, Poyares D, Bittencourt LR, Santos-Silva R, Tufik S. Effects of aging on sleep structure throughout adulthood: a population-based study. Sleep Med 2014;15(4):401-9 .https://doi.org/ 10.1016/j.sleep.2013.11.791.

4. Lauderdale DS, Schumm LP, Kurina LM, McClintock M, Thisted RA, Chen JH, Waite L. Assessment of sleep in the national social life, health, and aging project. J Gerontol B Psychol Sci Soc Sci 2014;6(Suppl 2): S125-33. https://doi.org/10.1093/geronb/gbu092.

5. Şahįn G. The importance of physical activity level and exercise characteristics on sleep quality in older adults. Act Adapt Aging 2018;42(3):250-9. https://doi.org/10.1080/01924788.2017.1398039.

6. Vanderlinden J, Boen F, van Uffelen JGZ. Effects of physical activity programs on sleep outcomes in older adults: a systematic review. Int J Behav Nutr Phys Act 2020;17(1):11. https://doi.org/ 10.1186/s12966-020-0913-3.

7. 7. Leger $D$, Poursain $B$, Neubauer D, Uchiyama M. An international survey of sleeping problems in the general population. Curr Med Res Opin 2008; 24(1):307-17. https://doi.org/ 10.1185/030079907x253771.

8. Crowley K. Sleep and sleep disorders in older adults. Neuropsychol Rev $2011 ; 21(1): 41-53$. https://doi.org/ 10.1007/s11065-010-9154-6.

9. Jalali R, Mohammadi M, Vaisi-Raygani A, Salari N. The prevalence of sleep disorders among Iranian older adults: A systematic review and meta-analysis. Curr Psychol 2021(9):1-8. https://doi.org/ 10.1007/s12144-020-01252-8.

10. Murray K, Godbole S, Natarajan L, Full K, Hipp JA, Glanz K et al. The relations between sleep,time of physical activity,and time outdoors among adult women. PLoS One 2017;12(9) .https://doi.org/10.1371/journal.pone.0182013.

11. Cappuccio FP, Cooper D, D'Elia L, Strazzullo P, Miller MA. Sleep duration predicts cardiovascular outcomes: a systematic review and meta-analysis of prospective studies. Eur Heart J 2011;32(12):1484-92. https://doi.org/ 10.1093/eurheartj/ehr007.

12. Cappuccio FP, D'Elia L, Strazzullo P, Miller MA. Quantity and quality of sleep and incidence of type 2 diabetes: a systematic review and meta-analysis. Diabetes Care 2010;33(2):414-20. https://doi.org/ 10.2337/dc09-1124.

13. Krishnan P, Hawranik p. Diagnosis and management of geriatric insomnia (guide for nurse practitioner). J Am Acad Nurse Pract 2008;20(12):590-9. https://doi.org/ 10.1111/j.1745-7599.2008.00366.x.

Page $13 / 15$ 
14. Rahmani Nia F, Mohebi A, Saberian M. The effect of walking on quality, quantity and some of physiologic parameters related to sleep in elderly men. Journal of Sport Biosciences(JSB) 2009;1(3):111-26.

15. Yang PY, Ho KH, Chen HC, Chien MY. Exercise training improves sleep quality in middle-aged and older adults with sleep problems: A systematic review. J Physiother 2012; 58(3):157-63. https://doi.org/ 10.1016/S1836-9553(12)70106-6.

16. Harrington JJ, Lee-Chiong T. Sleep and olderpatients. Clin Chest Med 2007;28(4):673-84. https://doi.org/ 10.1016/j.ccm.2007.07.002.

17. Khajavi D, Khanmohamadi R. The effect of "Green Exercise" on improving the sleep quality of female elderly without regular physical activity in Arak city. Journal of Women and Family Studies(JWFS) 2016;3(2):7-32. https://doi.org/10.22051/JWFS.2016.2206.

18. Petit L AN, Byszewski A, Sarazan F, Power B. Non-pharmacological management of primary and secondary insomnia among older people: review of assessment tools and treatments. Age Ageing 2003;32(1): 19-25. https://doi.org/ 10.1093/ageing/32.1.19.

19. Akbari Kamrani AA, Shams A, Shamsipour Dehkordi P, Mohajeri R. The effect of low and moderate intensity aerobic exercises on sleep quality in men older adults. Salmand: Iran J Ageing 2016;11(4):72-81.

20. Varrasse M, Li J, Gooneratne N. Exercise and sleep in community-dwelling older adults. Curr Sleep Med Rep 2015;1(4):232-40. https://doi.org/10.1007/s40675-015-0028-6.

21. World Health Organization [Internet]:Geneva, Switzerland, 2010. Global recommendations on physical activity for health. Available from: https://www.who.int/publications/i/item/9789241599979.

22. Warburton DE, Nicol CW, Bredin SS. Health benefits of physical activity: The evidence. CMAJ 2006;174(6):801-9. https://doi.org/ 10.1503/cmaj.051351.

23. Whitehead BR, Blaxton JM. Daily well-being benefits of physical activity in older adults: Does time or type matter? Gerontologist 2017;57(6):1062-71. https://doi.org/10.1093/geront/gnw250.

24. Zar A, Alavi S, Ahmadi F, Rezaie F, Mirghaderi F. Effects of physical activity and exercise on sleep quality in postmenopausal women. Iranian Journal of Obstetrics, Gynecology and Infertility (IJOGI) 2017;20(4):19-24. https://doi.org/ 10.22038/IJOGI.2017.8977.

25. Kohandel M, Sanatkaran A, Alikaram A. The comparison of cognition performance and sleep quality in older adults with different physical activity levels. Strategics Studies On Youth and Sports 2015;14(29):185-200.

26. Bahrami Einolgasi H, Khodabakhshi koolaee A, Taghvaee D. Efficacy of group physical activity on sleep quality and quality of life among older adults in Kahrizak nursing home. Journal of Gerontology (JOGE) 2016;1(1):29-39. https://doi.org/ 10.18869/acadpub.joge.1.1.45.

27. Wang $X$, Youngstedt SD. Sleep quality improved following a single session of moderate-intensity aerobic exercise in older women: Results from a pilot study. J Sport Health Sci 2014;3(4):338-42. https://doi.org/ 10.1016/j.jshs.2013.11.004.

28. Moodi M, Dehghani Firoozabadi M, Kazemi T, Payab M, Ghaemi K, Miri MR, et al. Birjand longitudinal aging study (BLAS): the objectives, study protocol and design (wave I: baseline data gathering). J Diabetes Metab Disord 2020; 19(1):551-9. https://doi.org/ 10.1007/s40200-020-00504-5.

29. Dadfar M, Kalibatseva Z, Lester D. Reliability and validity of the Farsi version of the Patient Health Questionnaire-9 (PHQ9) with Iranian psychiatric outpatients. Trends Psychiatry Psychother 2018;40(2):144-51. https://doi.org/ 10.1590/22376089-2017-0116.

30. Hedayat S, Arefi M. The effect of cognitive-behavioral therapy on improving sleep quality in the elderly. Knowl Res Appl Psychol 2015; 16 (2) :60-8.

31. Nam GB. Exercise, heart and health. Korean Circ J 2011; 41(3): 113-21. https://doi.org/ 10.4070/kcj.2011.41.3.113.

32. Stel VS, Smit JH, Pluijm SM, Visser M, Deeg DJ, Lips P. Comparison of the LASA Physical Activity Questionnaire with a 7day diary and pedometer. J Clin Epidemiol 2004;57(3):252-8. https://doi.org/ 10.1016/j.jclinepi.2003.07.008.

33. Dzierzewski JM, Buman MP, Giacobbi PR, Roberts BL, Aiken - Morgan AT, Marsiske M, McCrae CS. Exercise and sleep in community - dwelling older adults: evidence for a reciprocal relationship. J Sleep Res 2014; 23(1): 61-8. https://doi.org/

Page $14 / 15$ 
10.1111/jsr.12078.

34. Li J, Yang B, Varrasse M, Ji X, Wu M, Li Ma, Li K. Physical activity in relation to sleep among community-dwelling older adults in China. J Aging Phys Act 2018; 26(4):647-54. https://doi.org/ 10.1123/japa.2017-0270.

35. Kredlow, MA, Capozzoli MC, Hearon BA, Calkins AW, Otto MW. The effects of physical activity on sleep: a meta-analytic review. J Behav Med 2015; 38 (3): 427-49. https://doi.org/ 10.1007/s10865-015-9617-6.

36. Štefan L, Vrgoč G, Rupčić T, Sporiš G, Sekulić D. Sleep duration and sleep quality are associated with physical activity in elderly people living in nursing homes. Int J Environ Res Public Health 2018;15(11):2512. https://doi.org/ 10.3390/ijerph15112512.

37. Wu CY, Su TP, Fang CL, Yeh Chang M. Sleep quality among community-dwelling elderly people and its demographic, mental, and physical correlates. J Chin Med Assoc 2012;75(2):75-80. https://doi.org/ 10.1016/j.jcma.2011.12.011.

38. Garfield V, Llewellyn $\mathrm{CH}$, Kumari $\mathrm{M}$. The relationship between physical activity, sleep duration and depressive symptoms in older adults: The English Longitudinal Study of Ageing (ELSA). Prev Med Rep 2016; 4:512-16. https://doi.org/ 10.1016/j.pmedr.2016.09.006.

39. Hartescu I, Morgan K, Stevinson CD. Sleep quality and recommended levels of physical activity in older people. J Aging Phys Act 2016; 24(2):201-6. https://doi.org/ 10.1123/japa.2014-0061.

40. Jacobs JM, Cohen A, Hammerman-Rozenberg R, Stessman J. Global sleep satisfaction of older people: the Jerusalem Cohort Study. J Am Geriatr Soc 2006;54(2):325-9. https://doi.org/ 10.1111/j.1532-5415.2005.00579.x.

41. Park S. Associations of physical activity with sleep satisfaction, perceived stress, and problematic Internet use in Korean adolescents. BMC Public Health 2014; 14:1143. https://doi.org/ 10.1186/1471-2458-14-1143.

42. Abraham O, Pu J, Schleiden LJ, Albert SM. Factors contributing to poor satisfaction with sleep and healthcare seeking behavior in older adults. Sleep Health 2017;3(1):43-8. https://doi.org/ 10.1016/j.sleh.2016.11.004.

43. Albert SM, Roth T, Toscani M, Vitiello MV, Zee P. Sleep health and appropriate use of OTC sleep aids in older adultsrecommendations of a Gerontological Society of America workgroup. Gerontologist 2017;57(2):163-70. https://doi.org/10.1093/geront/gnv139.

44. Silva MRd, Ferretti F, Pinto SdS, Filho OFT. Depressive symptoms in the elderly and its relationship with chronic pain, chronic diseases, sleep quality and physical activity level. BrJP 2018;1(4):293-8. https://doi.org/10.5935/25950118.20180056 .

45. Hsu MF, Lee KY, Lin TC, Liu WT, Ho SC. Subjective sleep quality and association with depression syndrome, chronic diseases and health-related physical fitness in the middle-aged and elderly. BMC Public Health 2021; 21(1): 164-73. https://doi.org/ 10.1186/s12889-021-10206-z.

46. Hall JE. Guyton and Hall: Tratado de fisiologia medica. 12th ed. Rio de Janeiro: Guanabara Koogan; 2011.

47. Powers SK, Howley ET. Fisiologia do exercício: Teoria e aplicação ao condicionamento e ao desempenho. 8th ed. São Paulo: Manole; 2014. 